\title{
Comparative Study of Spawn Development of Blue Oyster Mushroom [Hypsizygus ulmarius (Bull.:Fr.) Redhead] in Different Grains
}

\author{
Ankireddypalle Bhuvanesh Reddy*, Sobita Simon, \\ Abhilasha A. Lal and Hemanth Kumar
}

Department of Plant Pathology, Naini Agricultural Institute, Sam Higginbottom University of Agriculture Technology and Sciences, Prayagraj and Uttar Pradesh, India

*Corresponding author

\section{A B S T R A C T}

\begin{tabular}{|l|}
\hline K e y w or d s \\
Hypsizygus \\
ulmarius, Spawn, \\
Mycelial, \\
Primordial \\
initiation, Fruiting \\
body, Pileus, Stipe, \\
Flush
\end{tabular}

Hypsizygus ulmarius is popularly known as 'Blue oyster mushroom' or 'Elm oyster mushroom'. It has been gaining popularity in recent times because of its unique meaty flavour and blue coloured pinheads. The major constraint in mushroom production is spawn preparation which requires high investment, sophisticated equipment and highly skilled technician. The present investigation was carried out to find the best substrate for spawn preparation and cultivation of Hypsizygus ulmarius in Laboratory and Mushroom Crop Room, Department of Plant Pathology, SHUATS, Prayagraj, Uttar Pradesh, India. Six locally available different grains viz., wheat, paddy, sorghum, bajra, maize, and barley were tested for production of $H$. ulmarius spawn with wheat grains as control. The results of the present investigation showed that mycelial colonization of H.ulmarius was faster in sorghum grains which took 16.67 days for complete formation of spawn. Whereas spawn development of $H$. ulmarius in remaining grains varies among themselves as bajra grains (17.67 days), paddy grains (18.33 days), wheat grains (18.67 days), maize grains (25 days), and barley grains (28.67 days), respectively.

\section{Introduction}

Mushrooms are macroscopic, spore bearing, fruiting bodies belonging to the kingdom Fungi, division Eumycota, sub-division Basidiomycotina. Mushrooms were first grown by a French gardener. Mushrooms were known to be cultivated around the year 600 A.D in Asia for the first time. Mushrooms were introduced in Europe in $17^{\text {th }}$ century. However, in $19^{\text {th }}$ century, mushrooms were started to be cultivated on a large scale. The flavor and nutritional value of mushrooms started to attract the people. Mushrooms are valuable food possessing low calories, but high in crude protein, vitamins and minerals. The mineral content in mushrooms is superior to that of meat and nearly that of the most commonly used vegetables (Joshi et al., 2018). The niacin content is about ten times greater than any other vegetables. Thus the demand for the mushrooms started to increase in enormous rate. 
Hypsizygus ulmarius (Bull.:Fr.) Redhead is one among the many species of oyster mushrooms found in India. It is commonly called as 'Elm oyster mushroom' or 'Blue oyster mushroom' (Sumi and Geetha, 2016). It was introduced for the first time in India for commercial production by Indain Institute of Horticulture Research, Bangalore, Karnataka (Padmavathi and Rajini, 2017).It is a high yielding mushroom for which commercial cultivation technology has been released and is gaining popularity. It is similar to oyster mushroom, but differs in morphology and biological efficiency. It is a very unique mushroom with large fruiting body, blue colored pinheads becoming light white on maturity and is a high yielder. This mushroom is palatable with meaty flavor and attractive keeping qualities. Despite these attractive qualities, its production in tropical climate should need to be fully explored (Sumi and Geetha, 2016). Medically, it is known for its cardiovascular, antitumour and cholesterol controlling properties.

The mushroom cultivation is based upon two prominent steps namely spawn preparation and mushroom production. Spawn can be termed as the seed of mushroom fungi. Spawn preparation is a technical procedure which involves transfer of pure culture of mushroom fungi to the sterilized grains under aseptic conditions.

Spawn can be grown on wide range of materials like grains, dung, cardboards, papers, saw dust etc. Grains are gaining huge popularity in recent days and are being proven as best substrates for spawn production. Also, the leftover grain material can be useful to produce the spawn.

The present study was under taken with a view to find the best substrate for spawn preparation by evaluating the effect of different grains viz., wheat, paddy, sorghum, bajra, maize, and barley on spawn production of the blue oyster mushroom H. ulmarius.

\section{Materials and Methods}

\section{Experimental site}

The experiment was carried out in the Laboratory and Mushroom Crop Room, Department of Plant Pathology, SHUATS, Prayagraj, Uttar Pradesh, India during the period from August, 2019 to March, 2020.

\section{Pure culture of mushroom}

The pure culture of Hypsizygus ulmarius was procured from Directorate of Mushroom Research, Solan, Himachal Pradesh, India. The pure culture was further sub-cultured using PDA (Potato Dextrose Agar) media and incubated at $25 \pm 1^{0} \mathrm{C}$ until substantial growth of mycelium was observed. This mycelium was used for the spawn preparation of $H$. ulmarius.

\section{Substrates for spawn preparation}

The grains viz., wheat, paddy, sorghum, bajra, maize, and barley were selected on the basis of ease of availability and economic feasibility, with the view to evaluate their effect on the mycelial growth of Hypsizygus ulmarius for spawn preparation.

\section{Preparation of spawn}

The grains were washed with water. The dirt and damaged grains were removed. All the grains were soaked overnight individually. On the next day, the grains were boiled separately in a vessel for 30 minutes until the grains gets soften. Over cooking must be avoided in order to prevent the breakage of the seed coat. Such grains should not be used for spawn preparation. The cooked grains were spread evenly on a cloth to get cooled and to remove 
excess water. At 50\% moisture level, $0.3 \%$ calcium carbonate and $1.2 \%$ gypsum were added to the cooled grains thoroughly to avoid the sticking of grains (Deharia and Vyas, 2015; Pradeep et al., 2018). The grains were filled in $500 \mathrm{ml}$ conical flasks up to $2 / 3^{\text {rd }}$ height, below the neck and the cotton plugs were plugged. The conical flasks along with the grains were sterilized in the autoclave at $121^{\circ} \mathrm{C}$ at $15 \mathrm{lbs}$ pressure for 2 hours (Mishra et al., 2018). The conical flasks were removed from autoclave and were kept in the laminar air flow cabinet under the UV light (Kudada et al., 2017). The UV light was turned off after 45 minutes and the working light and air blower were turned on. Under aseptic conditions, the radial discs of pure cultures were transferred into the conical flasks and the cotton plugs were plugged tightly. A piece of aluminum foil was wrapped around the cotton plug in order to prevent the contamination. The conical flasks were stored in an incubator at $25 \pm 1^{0} \mathrm{C}$. The conical flasks were checked for contamination at every two days interval. Shaking of the conical flasks was done at every 3 days interval in order to facilitate better mycelial colonization around the grains. When the mycelium completely covers the grains, then the spawn is ready to use

\section{Experimental design}

In this experiment, completely randomized design (CRD) was used and the six treatments were replicated thrice.

\section{Data analysis}

The conclusions were drawn on the basis of analysis of variance (ANOVA) using OPSTAT. The calculated $\mathrm{F}$ value was compared with the tabulated value at $5 \%$ level of probability at the appropriate degree of freedom (Fisher and Yates, 1986).

\section{Results and Discussion}

\section{Effect of different grain substrates on spawn growth}

The experiment was carried out in order to find out the best substrate for the spawn production of blue oyster mushroom. Among all the different substrates used, sorghum grains (16.6 days) took least time for the spawn preparation. While the remaining substrates took considerable time for spawn preparation which varies among themselves i.e., bajra grains (17.67 days), paddy grains (18.33 days), maize grains (25 days), barley grains (28.67 days) and wheat grains (18.67 days). The mycelial colonization of Hypsizygus ulmarius was very faster in sorghum grains than other grains used in the experiment.

As per the findings from this study, it was observed that the minimum days required for the growth of mycelium of Hypsizygus ulmarius were recorded in sorghum grains (16.67 days) whereas, the maximum time required for spawn development was observed in barley grains (28.67 days). The results obtained were very close to another study by Pandey et al., (2017) who reported that minimum days required for spawn development of Pleurotus flabellatus was recorded in sorghum grains (7.75 days). Similar results were obtained by Khatri and Agrawal (2002) that early development of spawn was observed in sorghum grains which took minimum time. Better mycelial growth was observed in sorghum grains than others as reported by Sagir and Yildiz (2004). Also, Kudada et al., (2017) concluded that sorghum grains (20.5 days) took less time for the complete colonization of Calocybeindica, while maize grains (22.75 days)recorded the longest period for spawn formation. The probable reason for the variation in the colonization may be due to the variation in 
moisture levels of the grains during boiling. Furthermore, the sorghum grains size is smaller among the treatments used. Because of which the number of inoculation points are more as the number of grains per ounce is greater (Mamiro and Royse, 2008) (Fig. 1).

Fig.1 Effect of treatments on number of days required for the spawn formation by Hypsizygus ulmarius

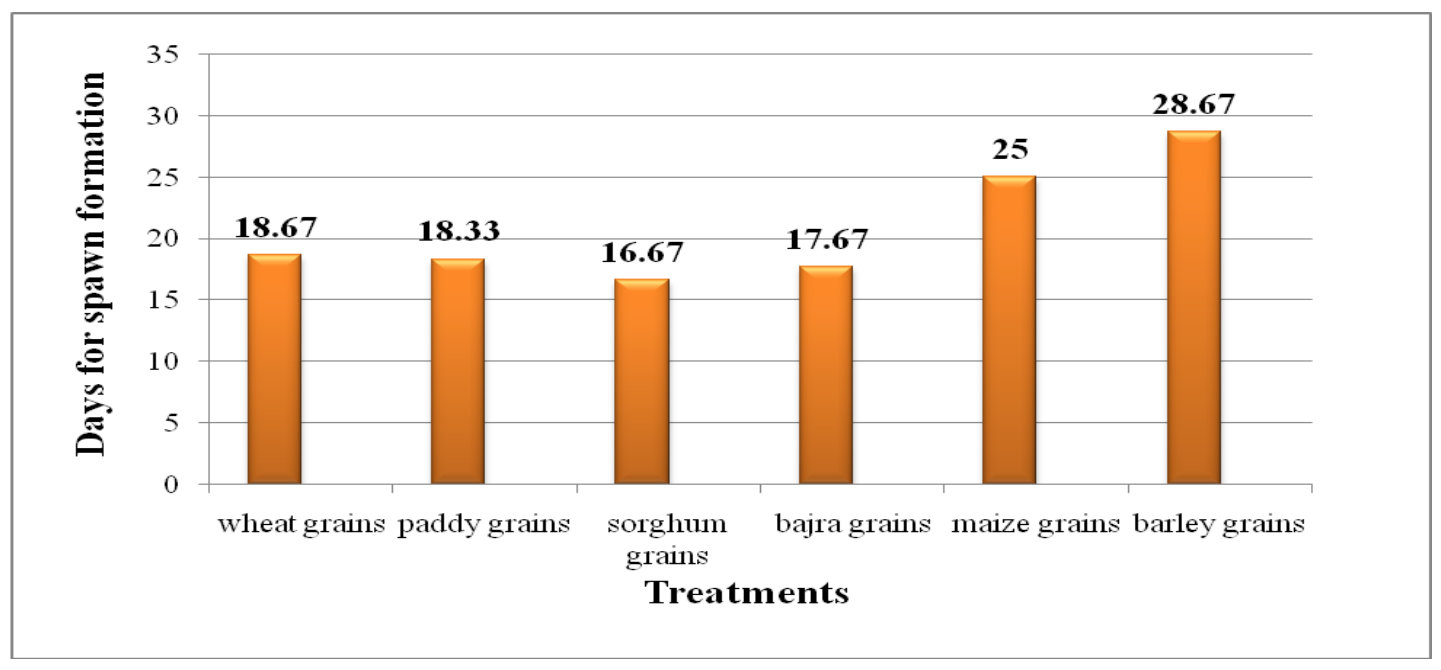

In conclusion as per the results obtained from this study, the sorghum grains were proved to be the best substrate for spawn preparation of Hypsizygus ulmarius, which took less time for complete mycelial colonization. Thus, sorghum grains can be used as a substrate for the spawn production of Hypsizygus ulmarius, as the sorghum grains are economically feasible and easily available. However, the results are of one cropping season (20192020) under Prayagraj agro-climatic conditions. As such to validate the findings more such trials should be taken up in the future.

\section{References}

Deharia, P. and Vyas, D. (2015). Evaluation of different spawns and substrates on growth and yield of Pleurotus sajorcaju. International Journal of Research Scientific Research. 6(3): 2908-2911.

Fisher, R.A. and Yates (1968). Statistical method for research workers. Oliver and Boyd ltd, Edinburgh and London.
10.

Joshi, S., Borkar, P.G., Saykar, A.D. and Pawar, S.V. (2018). Assessment of biological efficiency of Pleurotus sajorcaju, P. florida, P. citrinopileatus and Hypsizygus ulmarius. International Journal of Chemical Studies. 6(4): 2299-2301.

Khatri, R.K. and Agrawal, K.C. (2002). Effect of different grains and used tea leaves on spawn development of Cantharellusspp. in comparison to Pleurotus florida. Journal of Mycology and Plant Pathology.32(3): 431-432.

Kudada, N., Saurabh, A. and Kumari, N. (2017). Impact of spawn substrates on sporophore development and yield of milky mushroom (Calocybe indica). International Journal of Agricultural Science and Research. 7(3): 55-66.

Mamiro, D.P. and Royse, D.J. (2008). The influence of spawn type and strain on yield, size and mushroom solids content of Agaricus bisporus produced on noncomposted and spent mushroom 
compost. Bioresource Technology. 99(8): 3205-3212.

Mishra, A.M., Singh, G., Kumar, A., Yadav, A.K. and Mohit, K. (2018). Comparative studies of span growth on different grains substrate in three Pleurotus spp. (Pleurotusflorida, Pleurotus flabellatus and Pleurotus sapidus). International Journal of Current Microbiology and Applied Sciences. 7(6): 3239-3245.

Padmavathi, T. and Rajini, R. (2017).Spent mushroom substrate of Hypsizygus ulmarius: A novel multifunctional constituent for mycorestoration and mycoremediation. Biotechnology for Sustainability.88-103.

Pandey, N., Kerketta, A., Sahu, B. and Singh, H.K. (2017).Screening of suitable grains substrates for spawn development, growth and yield of
Pleurotus flabellatus. Research Journal of Agricultural Sciences. 8(2): 536-541.

Pradeep, K., Gopal, S., Amarpal, S., Sandeep, K., Mohit, and Kannaujia, J.P. (2018). Studies on effect of different substrates spawn rates on production of oyster mushroom (Pleurotus florida). Bulletin of Environment, Pharmacology and Life Sciences. 7(4): 25-29.

Sagir, A. and Yildiz, A. (2004).Growth of mycelium of Pleurotus spp. on different grains and determination of their competition with some contaminant fungi.ActaAlimentaria.33(3): 249-257.

Sumi, I. and Geetha. D. (2016). Physiological and cultural studies on blue oyster mushroom, Hypsizygus ulmarius (Bull.:Fr.) Redhead. International Journal of Applied and Pure Science and Agriculture. 2(6): 33-38.

\section{How to cite this article:}

Ankireddypalle Bhuvanesh Reddy, Sobita Simon, Abhilasha A. Lal and Hemanth Kumar. 2020. Comparative Study of Spawn Development of Blue Oyster Mushroom [Hypsizygus ulmarius (Bull.:Fr.) Redhead] in Different Grains. Int.J.Curr.Microbiol.App.Sci. 9(12): 23692371. doi: https://doi.org/10.20546/ijcmas.2020.912.281 